\title{
Justicia transicional y producción cultural: una cala en la transgresión literaria de los discursos institucionales de Argentina, Chile y España
}

\author{
Luisa García-Manso \\ Universidad de Utrecht
}

\begin{abstract}
Resumen:
El término 'justicia transicional' fue adoptado en los años 90 en las Ciencias Sociales y Jurídicas para hacer referencia al conjunto de medidas emprendidas en distintos países para lidiar con legados estatales de violaciones de los derechos humanos: juicios penales, comisiones de verdad, medidas de reparación de las víctimas, políticas de memoria y diferentes formas de reforma institucional, entre otros (Greiff 18). Dichas medidas, que beben de una tradición jurídica internacional, se están efectuando de manera diferente en los diversos países implicados en la confrontación con el pasado. En este ensayo tomo como ejemplo una selección de producciones culturales argentinas, chilenas y españolas de diverso tipo —narrativa, teatro y cine documental - en las que se problematizan los vacíos dejados por las reformas políticas y legales y por la perpetuación —especialmente en los casos español y chileno- de leyes de amnistía que dilatan la impunidad de los responsables de crímenes de lesa humanidad, reconocidos por la ONU como delitos imprescriptibles. Las producciones seleccionadas para el análisis tienen como denominador común su habilidad para denunciar los huecos dejados por la norma a través de recursos formales y expresivos con los que se transgreden los discursos institucionales - e institucionalizados - sobre memoria y justicia en los tres países.
\end{abstract}

Palabras clave: memoria, derechos humanos, narrativa, teatro, cine documental

\begin{abstract}
:
The term 'transitional justice' is first used in the 90s in the field of Social and Legal Sciences. It "refers to the set of measures implemented in various countries to deal with the legacies of massive human rights abuses", such as "criminal prosecutions, truth-telling, reparations, and different forms of institutional reform" (Greiff 18). In the diverse countries dealing with the past, these measures, which stem from an international legal tradition, are put into practice differently. In this essay, I examine how a selection of Argentinean, Chilean and Spanish cultural productions question the gaps in the political and legal reforms. Especially in the Spanish and the Chilean cases they criticise the perpetuation of amnesty laws that grant impunity to the people responsible for crimes against humanity. From the UN perspective, those crimes are not subject to statutory limitations. The chosen cultural productions belong to different genres: narrative, theatre and documentary film. They have in common the ability to denounce the legal vacuum through formal and expressive resources that transgress the institutional —and institutionalised - discourses on memory and justice of the three countries.
\end{abstract}

Keywords: memory, human rights, narrative, theatre, documentary film 
El término 'justicia transicional' fue adoptado en los años 90 en las Ciencias Sociales y Jurídicas para hacer referencia al conjunto de medidas políticas y legales que se emprenden en un país para lidiar con legados estatales de violaciones de los derechos humanos. Entre sus finalidades se hallan el reconocimiento de las víctimas, la promoción de la paz y la reconciliación y la consolidación democrática (International Center for Transitional Justice 1). Las medidas que habitualmente se reconocen dentro del ámbito de la justicia transicional comprenden juicios penales, comisiones de verdad, programas de reparación de las víctimas, diferentes formas de reforma institucional y políticas de memoria. No obstante, según qué autor o autora se consulte, puede haber ciertas divergencias, por ejemplo, a la hora de nombrar las políticas de memoria como parte integrante de la justicia transicional. ${ }^{1} \mathrm{El}$ International Center for Transitional Justice señala, en todo caso, que la justicia transicional no se trata de una lista cerrada de medidas, pues cada país va incorporando nuevas fórmulas en su tratamiento político y legal de los crímenes (1).

Un aspecto clave que ha de ser considerado en relación con la justicia transicional es que no solo comprende las eventuales medidas tomadas durante los procesos de transición política hacia la democracia, sino también las medidas implementadas décadas después de la comisión de los crímenes, tras la consolidación democrática. De hecho, algunos investigadores, como Elster, afirman que la justicia transicional tiene lugar después de los períodos de transición política hacia la democracia y no durante los mismos. ${ }^{2}$ Durante las transiciones, los partidarios de la democracia han de lidiar con las autoridades del régimen dictatorial previo, que siguen contando con gran poder. La toma de medidas puede poner en peligro la emergente democracia, por lo que en muchos países, sobre todo en aquellos que responden a un tipo de transición 'pactada', se suelen promulgar leyes de amnistía que bloquean toda tentativa de perseguir penalmente los crímenes. Es el caso de los tres países en torno a los que voy a tratar en este artículo. Tanto España, como Argentina y Chile, cuentan en la actualidad o contaron en su momento con leyes que han impedido la investigación de los crímenes contra la humanidad cometidos en las pasadas dictaduras.

Por otra parte, la justicia transicional no puede entenderse sin tener en cuenta la experiencia histórica y transnacional de distintas formas y modelos de justicia postconflicto. Se trata de un campo de estudio eminentemente práctico, que se ha conformado a partir de experiencias históricas como las de los tribunales de Núremberg y Tokio después de la II Guerra Mundial, las transiciones hacia la democracia en el Sur y el Este de Europa y en Latinoamérica — estas últimas adscritas a lo que Huntington denominó la 'tercera ola' de democratización-, los tribunales para la antigua Yugoslavia o Ruanda y la Comisión de Verdad y Reconciliación de Sudáfrica (Buckley-Zistel et al. 1). No es infrecuente, en consecuencia, encontrar titulares de prensa en los que se hace referencia a los asesores y actores internacionales que participan en negociaciones

${ }^{1}$ En los últimos años se observa una tendencia a incluirlas. No se puede negar el valor pedagógico de estas políticas y su papel a la hora de mediar frente a la sociedad y prepararla para comprender y aceptar otro tipo de medidas, desde las compensatorias hasta las penales. El hecho de que muchos estudios no las mencionen se debe, probablemente, a las tradiciones disciplinares que se han ocupado de abordarlas. Así lo entiende, por ejemplo, Barahona de Brito (359-60).

2 "Transitional justice is made up of the processes of trials, purges, and reparations that take place after the transition from one political regime to another" (Elster 1, el énfasis es mío). 
como las de la firma de la paz de Colombia (Lafuente). Los procesos de justicia transicional beben de experiencias transnacionales y del derecho comparativo e internacional. Todo esto hace inevitable la presencia de un enfoque transnacional en lo que se refiere a su estudio. Los manuales y estudios aparecen a menudo estructurados en forma de compendios y recuentos de las medidas tomadas en diversos países (Kritz; Greiff, Handbook), en ocasiones adoptando una perspectiva comparativa (Nino; Roniger y Sznajder; Barahona de Brito, González Enríquez y Aguilar), en la que se suelen apoyar los argumentos que apuntan hacia la idoneidad de desarrollar unas u otras medidas en países en los que los procesos están aún abiertos.

En un artículo de 2010, Barahona de Brito llamaba la atención sobre las relaciones entre los estudios sobre justicia transicional y los Estudios de la Memoria y señalaba que, a pesar de la confluencia de intereses de ambas áreas, apenas existen trabajos que las conectaran (Barahona de Brito 359). En los dos ámbitos el foco de atención recae en la forma en la que la sociedad se enfrenta a un pasado conflictivo, sin embargo, apenas hay estudios que integren ambas perspectivas, procedentes, la primera de ellas, de las ciencias políticas y el derecho, y la segunda, de la sociología, los estudios culturales y la psicología (359). Menos convergencias aún se han producido entre la justicia transicional y los estudios culturales. Se han realizado, eso sí, trabajos dedicados a indagar en las intersecciones entre las políticas de memoria y determinadas obras que abordan o conmemoran acontecimientos del pasado (Wilde; Natzmer; Resina y Winter; Winter; Werth), o los análisis de ciertas representaciones culturales y su papel en la defensa de los derechos humanos (Becker, Hernández y Werth; Luckhurst y Morin). Pero, por lo general, no existen estudios que tengan en cuenta la incidencia de otras medidas de justicia transicional en el ámbito cultural y viceversa. A mi manera de ver, un análisis transnacional de las producciones culturales en su relación con los procesos de justicia transicional puede arrojar luz sobre cómo las sociedades lidian con legados de crímenes contra la Humanidad y con las tensiones que se producen en la vida democrática ante la coexistencia de víctimas y victimarios, el papel jugado por la sociedad bajo la dictadura y la influencia, en definitiva, que el tratamiento legal y jurídico de los crímenes tiene sobre las sociedades actuales.

Como señalaba más arriba, la justicia transicional es un ámbito propicio para la transferencia de saberes y para compartir experiencias a nivel global. De hecho, los países latinoamericanos que en la actualidad se enfrentan a un legado de violaciones de los derechos humanos se apoyan en la experiencia tanto de los países vecinos, como de países al otro lado del océano. Tal y como señala Capdepón, "the public forms of dealing with a historical legacy of extreme violence and crimes have moved progressively into a global context and have created new forms of transatlantic entanglements, influences and alliances" (Capdepón citada en Assmann 555). Esta posibilidad de trasladar y compartir experiencias halla un desarrollo excepcional en el ámbito cultural y artístico. A través de paralelismos históricos y culturales, la literatura, el cine, el teatro y el arte, en general, dejan entrever el carácter supranacional de las experiencias de lucha por la justicia transicional. Pero, ¿qué papel desempeñan las producciones culturales en los procesos de justicia transicional? ¿Qué tipos de relaciones, convergencias y divergencias se establecen entre dichas producciones y medidas? Parto de la hipótesis de que la implementación o elusión de medidas de justicia transicional se manifiesta sintomáticamente en las producciones culturales a través de relatos, imágenes y repre- 
sentaciones que reflexionan sobre las violaciones de los derechos humanos y la polarización social entre víctimas y victimarios y entre los antiguos colaboradores de las fuerzas represivas y los miembros de la oposición política. Así pues, es posible estudiar las producciones culturales como un reflejo de las demandas sociales y políticas a favor de la justicia transicional. Pero las producciones culturales también pueden ayudar a visibilizar y divulgar los motivos por los que es importante implementar ciertas medidas legales y políticas (Greiff, "Invisible" 17). Por ello, los productos culturales también han sido utilizados como una herramienta de la justicia transicional, dada su capacidad para conmover al público y para modificar ideas preconcebidas y expectativas. ${ }^{3}$

Sin embargo, la influencia entre cultura y justicia transicional no es unidireccional, puesto que las producciones culturales también pueden interpelar a los agentes políticos y a la sociedad a realizar cambios, habiéndose dado ya casos en los que los testimonios vertidos en un texto literario, teatral o audiovisual han sido utilizados en juicios penales como prueba. ${ }^{4}$ Por otra parte, incluso en aquellos países en los que se han tomado diversas medidas de justicia transicional, las producciones culturales pueden convertirse en una vía de reflexión que permita ir más allá de los discursos institucionalizados y señalen sus limitaciones, como ocurre en las obras que voy a tratar a continuación. Para el análisis voy a referirme brevemente a tres obras de diversos géneros y países en los que se transgreden esos lenguajes institucionalizados: un documental chileno que puede describirse como experimento sociológico sobre la transmisión y recepción del pasado y la memoria - El astuto mono Pinochet contra la Moneda de los cerdos (2004), de Bettina Perut e Iván Osnovikoff-, un monólogo teatral grotesquizante de una autora española — "Un hueso de pollo" (2009), de Laila Ripoll-, y un diario autoficcional de una autora argentina - Diario de una princesa montonera (2012), de Mariana Eva Perez-. A pesar de las diferencias enunciativas y discursivas de las tres obras, todas ellas coinciden en problematizar los vacíos dejados por la norma y por la perpetuación - especialmente en los casos español y chileno- de leyes de amnistía que dilatan la impunidad de los responsables de crímenes de lesa humanidad, reconocidos por la ONU como delitos imprescriptibles.

\section{Una cala en la transgresión cultural de los discursos institucionalizados en torno a procesos abiertos de justicia transicional}

Comienzo, siguiendo un orden cronológico, por El astuto mono Pinochet contra la Moneda de los cerdos (2004), de Bettina Perut e Iván Osnovikoff, un documental chileno en el que se plantea el tema de la visión del pasado transmitida a las generaciones que nacieron después del golpe de Estado de Pinochet y que vivieron la dictadura como niños o que incluso nacieron ya en la democracia. El documental se propone así realizar un experimento social sirviéndose de los recursos de la ficción y la performance, con el fin de revelar qué imágenes del gobierno de Allende, del golpe de Estado y de la dicta-

\footnotetext{
${ }^{3}$ Un ejemplo se halla en la Antígona de José Watanabe llevada a escena por el Grupo Cultural Yuyachkani en Perú. Una de las finalidades del drama era animar a potenciales testigos a acudir a declarar a la Comisión de la Verdad y Reconciliación (Taylor; A’Ness; Lambright; Alonso; Robles-Moreno).

${ }^{4}$ Así ocurre, por ejemplo, con el documental $M$ (2007), del director argentino José Prividera, el cual fue presentado como prueba en las causas sobre el secuestro de su madre (Ciancio 508).
} 
dura de Pinochet prevalecen a la altura de 2004 en la conciencia de las jóvenes generaciones. Para ello utilizan una fórmula original y transgresora de los habituales medios del género, ya que en lugar de preguntarles qué saben de ese pasado y realizar un documental de investigación, lo que les piden es que preparen una representación grupal o juego - a través de improvisaciones- al respecto. Como señala Ros, de esta manera lograron que estos expresaran las contradicciones, simplificaciones y distorsiones que rodean la memoria del conflicto (137). Así pues, en la película se documentan las ficciones creadas por grupos escolares y universitarios pertenecientes a distintos estratos sociales. ${ }^{5}$ La fecha de realización del documental es significativa, puesto que el inicio del proyecto, en 2003, coincidió con la conmemoración del trigésimo aniversario del golpe de Estado.

Se trata de un documental poco convencional, en el que las secuencias se fragmentan y yuxtaponen para evocar una gran diversidad de voces y puntos de vista sobre los hechos históricos. Participan un total de diez grupos con sus improvisaciones y escenificaciones, sobre los que los directores superponen música y sonidos como, por ejemplo, canciones que marcaron la época, ruido de bombas o las ya conocidas comunicaciones radiofónicas ${ }^{6}$ entre los golpistas que se conservan del 11 de septiembre de 1973. Al comienzo, en una secuencia en la que un grupo de niños busca un título para el documental, escuchamos cómo una niña se queja a un compañero y le dice: "ah, sólo porque tú eres de Pinochet...”. De manera inocente, los niños revelan un posicionamiento que por su corta edad no puede ser propio sino heredado, aprendido. En un tono lúdico que a veces se vuelve incómodo, cuando los participantes comienzan a enfrentar sus ideas reales sobre los hechos, vemos desencadenarse escenas que van desde la grabación de un cortometraje de factura melodramática hasta las discusiones en torno a las diferencias económicas y de oportunidades de dos compañeros de distinta clase social.

El documental de Perut y Osnovikoff se aleja, por lo tanto, de los planteamientos habituales, más o menos institucionalizados, de la memoria, y evita también la perspectiva testimonial que en otro tipo de trabajos otorgan las víctimas, victimarios y testigos de los hechos. Con una mirada irreverente, que se destaca ya en el título del documental, ${ }^{7}$ los creadores buscan provocar una reacción en el público a través de la contemplación de los juegos aparentemente inocentes de los niños y jóvenes, que acaban desembocando casi en todos los casos en violencia e incluso en discusiones que se salen del ámbito de la ficción. En las distintas interpretaciones generadas por los estudiantes sobre la jornada del golpe de Estado se nos muestran hasta tres tipos de muertes diferentes del presidente Allende: en forma de suicidio; como parte de las bajas ocasionadas por el bombardeo de la Moneda; y en manos del propio Pinochet y

${ }^{5}$ Los centros implicados fueron: la Escuela de Cine UNIACC, el Colegio La Maison de l'Enfant, el Liceo Héroes de la Concepción, el Colegio El Encuentro, la Escuela de Derecho de la Universidad Alberto Hurtado, el Instituto Nacional General José Miguel Carrera, el Liceo Pablo de Rokha, el Colegio Sagrados Corazones de Providencia y la Escuela de Teatro de la Universidad de Chile. A pesar de que trataron de incluir centros de tradición pinochetista, su proyecto no fue bienvenido allí.

${ }^{6} \mathrm{La}$ comunicación radiofónica que mantuvieron los jefes de las Fuerzas Armadas durante el 11 de septiembre de 1973 fueron grabadas por un radioaficionado y mantenidas ocultas hasta su publicación en CD junto con el libro y la investigación de Patricia Verdugo, Interferencia secreta (1998) (Pagni 17).

${ }^{7} \mathrm{El}$ título del documental fue diseñado por uno de los grupos escolares participantes de menor edad, durante una tormenta de ideas que se muestra en al comienzo de la película. 
sus secuaces, en una terrible secuencia en la que unos niños simulan torturas con descargas eléctricas.

En esas secuencias predomina la improvisación y espontaneidad de los niños, pero también se incluyen escenificaciones de carácter más profesional y que parten de un guion previo, como el cortometraje Llora pero no olvides, realizado por el alumnado de la Escuela de Cine, cuya grabación y ensayos se muestran parcialmente en un ejercicio metaficcional. ${ }^{8}$ En el corto vemos cómo se filman una serie de escenas que componen la historia de una familia chilena, en la que el padre es un militar que participa en la detención, tortura y desaparición de su propio hijo, ante la ignorancia de la madre, quien es incapaz de distinguir que la mancha de sangre del uniforme de su marido no es, como este explica, de su nariz, sino de otra persona. En la escena final vemos a la madre guardando fotos de su hijo en una bolsa negra que luego entierra en el jardín, dando a entender que son los únicos restos que puede honrar de su hijo desaparecido.

Recursos metaficcionales hallamos también en las secuencias de los estudiantes de la Escuela de Derecho de la Universidad jesuita Alberto Hurtado, cuya propuesta consiste en representar opiniones diversas a través de un debate en torno a la cuestión “¿Fue legítima la intervención militar de 1973?” Algunos oradores esgrimen argumentos a favor, como, por ejemplo, que el golpe de Estado fue necesario para mejorar las condiciones de vida del pueblo o para evitar una guerra civil, ante lo que surge la pregunta de si el derramamiento de sangre fue preciso. En una de las secuencias, las fórmulas retóricas que los estudiantes utilizan en sus intervenciones se deconstruyen mediante rótulos que ponen en evidencia el carácter ficticio del debate $\mathrm{y}$, a su vez, la base real que tienen las ideas expresadas en la sociedad chilena.

En definitiva, el documental de Perut y Osnovikoff resulta transgresor tanto en lo que respecta a la ruptura de las formas tradicionales del género documental, como en sus contenidos, que ofrecen una mirada del pasado y el presente de Chile a través de las interpretaciones más o menos libres, más o menos conscientes, de las jóvenes generaciones.

Pasamos ahora a "Un hueso de pollo", un monólogo dramático escrito por Laila Ripoll que forma parte de la creación colectiva Restos, firmada por José Ramón Fernández, Rodrigo García, Laila Ripoll y Emilio del Valle. Se estrenó en la Sala Triángulo de Madrid el 2 de abril de 2009, un año y cuatro meses después de la promulgación de la que en España se conoce como Ley de Memoria Histórica (Boletín Oficial del Estado). Esta ley dio pie desde el primer momento a controversias, y contó con la oposición del PP — que la creía innecesaria — y de IU — que la consideraba insuficiente, al igual que la Asociación para la Recuperación de la Memoria Histórica, que vio en ella una oportunidad perdida para hacer justicia con respecto al pasado-.

El monólogo de Laila Ripoll denuncia la realidad de las fosas comunes a través de un discurso mordaz, teñido de humor negro, en el que el punto de vista se sitúa del lado de los victimarios para provocar un choque en el espectador y llamar la atención sobre la necesidad de llevar a cabo las exhumaciones y dar digna sepultura a las víctimas. A lo largo del monólogo se hace referencia a los desaparecidos como "pollos" y se da la receta para practicar la desaparición forzada de manera que las víctimas no puedan ser identificadas en el futuro. La oradora muestra orgullo patrio al haber sido

${ }^{8}$ Véanse los trabajos publicados por Lauge Hansen y Cruz Suárez para una profundización en la incidencia de la metaficción en las narrativas actuales sobre la memoria. 
España, según indica, pionera en estas prácticas, que posteriormente fueron exportadas a otros países, construyendo lo que ella denomina la "fosa global": "Luego ya vendrán otros que mejorarán la idea: alemanes, chilenos, argentinos, guatemaltecos, camboyanos, serbios, ruandeses. ¿No es hermoso? Todos los continentes, todos los países unidos en una maravillosa y emocionante fosa global" (Ripoll 126). Unas pocas frases bastan para conectar en el imaginario del público distintos contextos en los que se han cometido crímenes contra la Humanidad.

En tono de parodia, también, se critica la impunidad de los crímenes del franquismo mencionando los mismos argumentos que se esgrimieron en el parlamento y en la prensa detractora para criticar la Ley de Memoria Histórica: "No pretendan saber más de lo aconsejable, no sea que les motejen de guerracivilistas, o de rencorosos, o bien les acusen de abrir heridas o de pasarse por el forro de los cojones todo lo logrado con la transición" (127). El uso del humor negro, la ironía, el tono grotesco y paródico y el lenguaje soez suponen una vía para subvertir y criticar conceptos y discursos muy presentes en los medios de comunicación, que en ocasiones también se sirven de un lenguaje soez para desprestigiar las reclamaciones legítimas de los descendientes de las víctimas. También supone una crítica feroz y amarga la propuesta de las siguientes cuatro opciones, dirigidas a contrarrestar las tentativas de los familiares de hacer justicia y honrar a las víctimas:

La familia hace preguntas, la familia es molesta y la familia, de cara a la opinión pública, puede ser una malísima publicidad. Prescindamos pues, en la medida de lo posible, de la familia del pollo. Pero como esto suele resultar muy difícil, hay que buscar soluciones para el problema. Yo les propongo cuatro opciones: A) Negar los hechos con gallardía y testarudez. ¿Un pollo? ¿Qué pollo? ¿Dónde había un pollo? Yo no sé nada de un pollo. Eso es propaganda, eso es mentira. B) Echarle la culpa de todo al pollo: se suicidó, se enterró solo, era un bárbaro el pollo. C) Hacer desaparecer también a la familia del pollo. Mucho más práctico pero también más arriesgado ya que siempre se nos puede escapar alguno y ahí sí que la hemos cagado pero bien. D) Llevarnos a la familia a nuestro terreno y convencerla de que el pollo está en el mejor sitio en el que podía estar y de que no toquen más los cojones con el dichoso temita. ${ }^{9}$ (Ripoll 127)

Esta última cita me sirve para enlazar con la tercera obra, pues Mariana Eva Perez se refiere también irónicamente en su Diario de una princesa montonera. $-110 \%$ verdad- a las desapariciones forzadas a y la defensa de los derechos humanos como el "temita", siendo estas realidades que, como hija de desaparecidos, le afectan de primera mano. El Diario, publicado en 2012, nace como un blog en el que la autora ficcionaliza su propia biografía sirviéndose de recursos auto- y metaficcionales y con predominio de un tono sarcástico y mordaz, con el que va deslizando críticas a los discursos institucionalizados de la justicia y la memoria en Argentina. De especial interés es la transgresión de dichos discursos a través de juegos del lenguaje — por ejemplo, la narradora se refiere a los hijos desaparecidos como bijis y a la militancia como militontismoEstos recursos han sido ya analizados en estudios previos (Blejmar; Arenillas 52-53), por lo que me voy a detener en otros dos aspectos que se hallan muy presentes en el texto: el uso de la ficción como medio para señalar los límites de ciertas medidas de

\footnotetext{
${ }^{9} \mathrm{El}$ énfasis es mío.
} 
justicia transicional y el enfoque trasnacional y global en lo que respecta a la defensa de los derechos humanos y la lucha por la justicia.

A lo largo del texto se van introduciendo críticas, tanto por parte de la narradora como de sus eventuales interlocutores, en torno a un tipo de medidas de justicia transicional, las leyes reparatorias, "como las llama no sin violencia simbólica su órgano de ejecución” (Perez 49). En primer lugar, se alude a la Ley 25914, del año 2004. La narradora explica que "no es una ley para todos los hijis", es decir, que no todos los hijos de desaparecidos están incluidos. En consecuencia, el Diario registra cómo los implicados comienzan a organizarse y reunirse ante la convicción de que "si es una ley de hijis tenemos que entrar todos" (30). Más adelante, la narradora explica que en esas reuniones analizan las leyes y leen "la poca literatura académica" (48) que encuentran al respecto, pero el problema para ella reside en el propio lenguaje, en las deficiencias que presentan las leyes a la hora de nombrar y de amparar a las personas, y cómo estas permean en otros discursos, hasta el punto de que los propios boletines de las asociaciones pueden convertirse en "caballitos de troya de la prosa institucional" (64). Así pues, en la entrada del Diario en la que la narradora se refiere al fallecimiento de Néstor Kirchner, revela los sentimientos encontrados que le sugiere el recuerdo de su gobierno, y alude, entre otras medidas y gestos simbólicos, nuevamente a estas insuficientes leyes reparatorias, señalando que fueron "redactadas con el culo y nunca revisadas" (165).

Las críticas duras contra el anquilosamiento del lenguaje institucional y los límites de las medidas de justicia transicional adoptadas hasta el momento contrastan con el lenguaje utilizado para referirse a su trabajo en redes internacionales de solidaridad entre familiares de desaparecidos y a las experiencias de lucha contra la impunidad en otros países. Así pues, cuando viaja a Argelia en el marco de una red mundial de solidaridad, se identifica con las experiencias de otras mujeres y destaca el carácter global de sus padecimientos y su lucha: "La latitud es un azar, la lengua es un azar, la historia es la misma" (120). Se trata de fragmentos en los que el tono paródico cede paso a un discurso más íntimo, con el que se refiere a experiencias de lucha de otros países que reconoce como propias. Ahí es donde el carácter transnacional de los esfuerzos por reclamar la implementación de medidas de justicia transicional se pone en evidencia:

Reté a una madre viejita. Después del enésimo relato idéntico, la patota que no se identifica, el auto sin chapa, el hijo que no aparece más, el maltrato en la comisaría, las amenazas en el tribunal, lo de siempre, no pude más y le dije que si todos nos ponemos a contar estas historias y a llorar, no aprovechamos esta ocasión para pensar juntos nuevas estrategias de lucha. Es cierto, pero no es toda la verdad: soy yo que no tolero otro testimonio más. (Perez 115-116)

Otro ejemplo del carácter transnacional de las experiencias de lucha por la justicia transicional lo encontramos en el siguiente fragmento en el que se hace referencia a cómo las víctimas del franquismo comienzan a movilizarse imitando a las Madres de Plaza de Mayo: "Leo que después de la suspensión del juez Garzón, los familiares de las víctimas del franquismo comenzarán a manifestarse semanalmente emulando a —y no puedo seguir leyendo porque toda la congoja acumulada se me sube a la cabeza y tengo que sacarme los anteojos para taparme la cara y llorar a gritos [...]” (87).

La misma emoción despiertan en ella las canciones que conectan experiencias similares a ambos lados del Atlántico: 
Lloré con León Gieco, en esa época todavía podía llorar con eso de 'la memoria pincha hasta sangrar' o whatever. Lloré más cuando Serrat cantó: para la libertad/sangro, lucho y pervivo, y de eso no me avergüenzo porque Serrat le gustaba a Jose, es algo entre él y yo, y además es de Miguel Hernández, palabras mayores en todo lo que es autoflagelamiento hijístico. (177)

Hasta aquí llega mi rápido repaso de la transgresión de los discursos institucionales en las tres obras seleccionadas. Como he ido aduciendo, en la mente de las creadoras las conexiones entre las experiencias de dictadura de los distintos países y la lucha por la justicia se halla muy presente. Pero también se producen paralelismos entre las obras en el nivel estético. Es el caso, por ejemplo, de la proliferación de ciertos recursos que le dan una vuelta de tuerca a las formas tradicionales de representación, como la autoficción, la metaficción y la docuficción, que se han extendido en estos y otros países hispánicos a la hora de narrar las experiencias dictatoriales, muy especialmente en las creaciones de las generaciones de hijos y nietos, en las que el trabajo de memoria suele producirse a través de una mediación del recuerdo o de reconstrucciones fragmentarias. También se percibe esto en la utilización de lenguajes transgresores y de la estética del grotesco para aludir a lo que no es inefable, pero precisa de lenguajes ajenos a esos discursos ya institucionalizados y aceptados, para ser contado. De esta manera, las producciones culturales que responden a las demandas de justicia transicional, abarcan realidades que van más allá de lo local y que crean vasos comunicantes entre las formas de expresión y los contenidos plasmados por creadores y creadoras situados a ambos lados del Atlántico.

\section{Bibliografía}

Alonso, Laura. "La narración como situación enunciativa y el predominio del êthos en Antigona de José Watanabe y el Grupo Yuyachkani". Latin American Theatre Review 44.2 (2011): 55-67.

A’Ness, Francine. "Resisting Amnesia: Yuyachkani, Performance, and the Postwar Reconstruction of Peru". Theatre Journal 56.3 (2004): 395-414.

Arenillas, María. “'Ensayo en la noche’: Políticas de restitución en Diario de una princesa montonera-110\% verdad- de Mariana Eva Perez". V anderbilt e-Journal of Luso-Hispanic Studies 10 (2014): 50-58. Web. 2 julio 2018.

Assmann, Aleida. “Transnational Memories”. European Review 22.4 (2014): 546-556.

Barahona de Brito, Alexandra. "Transitional Justice and Memory: Exploring Perspectives". South European Society and Politics 15.3 (2010): 359-376.

Barahona de Brito, Alexandra, Carmen González Enriquez y Paloma Aguilar (Ed.). The Politics of Memory. Transitional Justice in Democratizing Societies. New York: Oxford University Press, 2001. 
Becker, Florian N., Paola S. Hernández y Brenda Werth (Ed.). Imagining Human Rights in Twenty-First-Century Theater. Global Perspectives. New York: Palgrave MacMillan, 2013.

Blejmar, Jordana. "Ficción o muerte: Autofiguración y testimonio en Diario de una princesa montonera-110\% verdad-”. Crítica Latinoamericana. Web. 27 julio 2017.

Boletín Oficial del Estado. Ley 52/2007, de 26 de diciembre, por la que se reconocen y amplían derechos y se establecen medidas a favor de quienes padecieron persecución o violencia durante la guerra civil y la dictadura. 27 de diciembre de 2007. Web. 2 julio 2018.

Buckley-Zistel, Susanne, Teresa Koloma Beck, Christian Braun y Friederike Mieth. Transitional Justice Theories. Oxon: Routledge, 2014.

Ciancio, Belén. “¿Cómo (no) hacer cosas con imágenes? Sobre el concepto de posmemoria". Constelaciones. Revista de Teoría Crítica 7 (2015): 503-515.

Elster, Jon. Closing the Books. Transitional Justice in Historical Perspective. Cambridge: Cambridge University Press, 2004.

Greiff, Pablo de (Ed.). The Handbook of Reparations. Oxford: Oxford University Press, 2006.

Greiff, Pablo de. "On Making the Invisible Visible: The Role of Cultural Interventions in Transitional Justice Processes". Transitional Justice, Culture, and Society. Beyond Outreach. Ed. Clara Ramírez-Barat. New York: Social Science Research Council, 2014. $10-24$.

Huntington, Samuel P. The Third W ave. Democratization in the Late Twentieth Century. Norman: University of Oklahoma Press, 1991.

International Center for Transitional Justice. "What is Transitional Justice?" (2009). Web. 2 julio 2018.

Kritz, Neil J. (Ed.). Transitional Justice. Volume II. Country Studies. Washington: United States Institute of Peace Press, 1995.

Lafuente, Javier. "El abogado español que encarriló a las FARC". El País (27 sep. 2016). Web. 2 julio 2018.

Lambright, Anne. "Dead Body Politics: Grupo Cultural Yuyachkani at Peru's Truth Commission". Imagining Human Rights in Twenty-First-Century Theater. Global Perspectives. Ed. Florian N. Becker, Paola S. Hernández y Brenda Werth. New York: Palgrave MacMillan, 2013. 27-44.

Lauge Hansen, Hans y Juan Carlos Cruz Suárez (Ed.). La memoria novelada. Hibridación de géneros y metaficción en la novela española sobre la guerra civily el franquismo (2000-2010). Bern/Berlin/Bruxelles et al.: Peter Lang, 2012.

Luckhurst, Mary y Emilie Morin (Ed.). Theatre and Human Rights after 1945. Things Unspeakable. Hampshire/New York: Palgrave Macmillan, 2015.

Natzmer, Cheryl. "Remembering and Forgetting. Creative Expression and Reconciliation in Post-Pinochet Chile". Social Memory and History. Anthropological Perspectives. 
Ed. Jacob J. Climo y Maria G. Gattell. Walnut Creek et al.: Altamira Press, 2002. 161-179.

Nino, Carlos Santiago. Radical Evil on Trial. New Haven/London: Yale University Press, 1996.

Pagni, Andrea. "Memoria y duelo en la narrativa chilena actual: ensayo, periodismo político, novela y cine". Memoria, duelo y narración. Chile después de Pinochet: literatura, cine, sociedad. Ed. Roland Spiller, Titus Heydenreich, Walter Hoefler y Sergio Vergara Alarcón. Frankfurt am Main: Vervuert, 2004. 9-27.

Perez, Mariana Eva. Diario de una princesa montonera. $-110 \%$ verdad-. Barcelona: Marbot, 2016.

Perut, Bettina e Iván Osnovikoff. El astuto mono Pinochet contra la Moneda de los cerdos. Chile, 2004. Film.

Resina, Joan Ramon y Ulrich Winter (Ed.). Casa encantada. Lugares de memoria en la España constitucional (1978-2004). Madrid/Frankfurt am Main: Iberoamericana/Vervuert, 2005.

Ripoll, Laila. “Un bueso de pollo.” Primer Acto 330 (2009): 126-128.

Robles-Moreno, Leticia. "Yo soy la hermana que fue maniatada por el miedo: Performance política y políticas de la memoria en Antígona, de Yuyachkani". Conflicto armado y políticas culturales de la memoria en el Perú. Ed. Carlos Vargas-Salgado. Hispanic Issues On Line (2016): 126-143. Web. 2 julio 2018.

Roniger, Luis y Mario Sznajder. The Legacy of Human-Rights Violations in the Southern Cone. Argentina, Chile, and Uruguay. New York: Oxford University Press, 1999.

Ros, Ana. The Post-Dictatorship Generation in Argentina, Chile, and Uruguay. Collective Memory and Cultural Production. New York: Palgrave Macmillan, 2012.

Taylor, Diana. The Archive and the Repertoire. Performing Cultural Memory in the Americas. Durham: Duke University Press, 2003.

Werth, Brenda. Theatre, Performance, and Memory Politics in Argentina. New York: Palgrave Macmillan, 2010.

Wilde, Alexander. "Irruptions of Memory: Expressive Politics in Chile's Transition to Democracy". Journal of Latin American Studies 31.2 (1999): 473-500. 